\section{Zur Richtigstellung.}

In Heft 3r dieser Zeitschrift benterkt Herr Dr. K. Norden in seiner Arbeit: „Ueber eine Methode zur Bestimnung der wahren Oberflächen von Akkumulatorplatten", Seite 397:

"Heim hat. zwar dieser Grösse" (nämlich der wahren, wirksamen Oberfläche, im Gegensatz zu der aus Länge und Breite der Platten sich ergebenden) ,in seinem Werkchen über Akkumulatoren die Bedeutung abgesprochen, weil die wahre Oberfläche doch nicht voli zur Wirkung gelangen kann, indem der Stron vorzugsweise durch vorspringende Teile der Platte einund austritt, tiefer liegende dagegen remeidet."

Ich muss vermuten, dass der Herr Verfasser sich die bezüglichen Stellen meiner Schrift nicht sorgfältig genug angesehen hat. Er würde sonst erkannt haben, dass es mir nicht eingefallen ist, einer Vergrösserung der elektrolytisch wirksanıen Oberfläche durch Riefeln der Platte oder dergl. "die Bedeutung abzusprechen", sondern dass meiner Ueberzeugung nach eine derartige Vermehrung der aktiven Oberfläche für die Erhöhung det Leistungsfähigkeit sehr wesentlich ist. Auf der ron Herrn Dr. Norden citierten Seite 15 heisst es nämlich:

"In Wirklichkeit ist die Stromdichte stets kleiner, weil die Oberfläche der Platten nicht eben und infolgedessen grösser ist, als oben angenommen. Die wahre Stromdichte genau anzugeben, ist jedoch nicht gut möglich, da auch die Verteilung der Stromstärke auf die einzelnen Teile der Plattenfläche nicht ganz gieichmässig ist, so zwar, dass alle Vorsprünge stärker beansprucht werden, als die Vertiefungen."

\title{
VEREINSNACHRICHTEN
}

\section{Deutsche Elektrochemische Gesellschaft.}

Anmeldungen zur Mitgliedschaft sincl satzungsgemäss an den ersten Vorsitzenden, Herru I'rofessor i) r. vall't Hoff, Charlottenburg, Uhlandstr. 2, zu richten; die Anmeldungen müssen von einem Mit. glied der Gesellschaft befürwortet seir1.

Zahlungen werden ausschliesslich an den Schatzmeister, Herrn Dr. Marquart, BettenhausenCassel, erbeten.

Alle anderen geschäftlichen Mitteiluugen wolle man an die Geschätsstelle der Deutsclien Elektrochemischen Gesellschaft, Leipzig, Mozartstr. 7 , richten.

Die Versendung der Vereinszeitschrift geschielıt durch die Verlagsbuch handlung unter deren Verantwortlichkeit Beschwerden über etwaige unregelmässige Zustellung der Vereinszeitschrift sind möglichst bald an die Geschäftsstelle zu richten. Es ist nicht möglich, Hefte unentgeltlich nachzuliefern, deren Fehlen nach Monaten oder erst an Jahresschlusse angezeigt wird.

An die neu eintretenclen Herren Mitglieder wird die Vereinszeitschrift erst nach Zahlung des Mitgliedbeitrages geliefert.

\section{Anmeldungen für die Mitgliedschaft.}

Gemäss $\$ 3$ der Satzungen werden hiernit die Namen der Herren, Firmen u. s. w., welche sich beim Vorstande für die Aufnahme gemeldet laben, veröffentlicht. Einspruch gegen die Anfnahme eines geneldeten Mitgliedes ist inuerlalls zweier lluchen (also bis zum 8. März einschliesslich) zu erheben.

Nr. 683. Haekeland, Dr. Leo, Chemiker, Yonkers on Hudson, near New York, L. S. A.; durch Max Kaehler \& Martini.

684. Accumulatorenwerke E. Schu1z, Witten an der Ruhr; durch J. Wershoven.

\section{Aufgenommene Mitglieder.}

Nr. 733. Zöh1s, Arthur, Giessen, Ludwigstr. 46.

"734. Gmünder, Heinrich, Giessen, Südanlage 7.

"735. Besson, Albert, Giessen, Bleichstr. 33

"736. Gaumer, Max, Giessen, Stefanstr. 11.

"737. Wipplinger, Christian, Giessen, Goethestrasse 52.

"738. Fischer, Dr. Iiranz, Giessen, Phys-Chem. Laborat., (ioethestrasse.

"739. Volney, C. W., Getueral-Manager der International Smokeless and Dynamite Co., South Amboy, N. J., U. S. A

"740. Meliring, Wilhelm, cand. chem., Giessen, Moltkestr. 8

"741. Silbermanu, F, caud. chem., Giessen, Moltkestr. 8

\section{Adressenänderung.}

Nr. 634. Palmaer, Dr. W., jetzt: Dozent der Elektrochemie an der Techn. Hochschule Stockholm.

\section{Ausgetreten.}

Nr. 5jo. Naturwissenschattlicher Verein Barmen (ab) I. Juli 1900)

Verantwortlicher Redakteur: Professor Dr.W. Borchers in Aachen. Druck und Verlag von Wilhelm Kapp in Halle a. S. 